
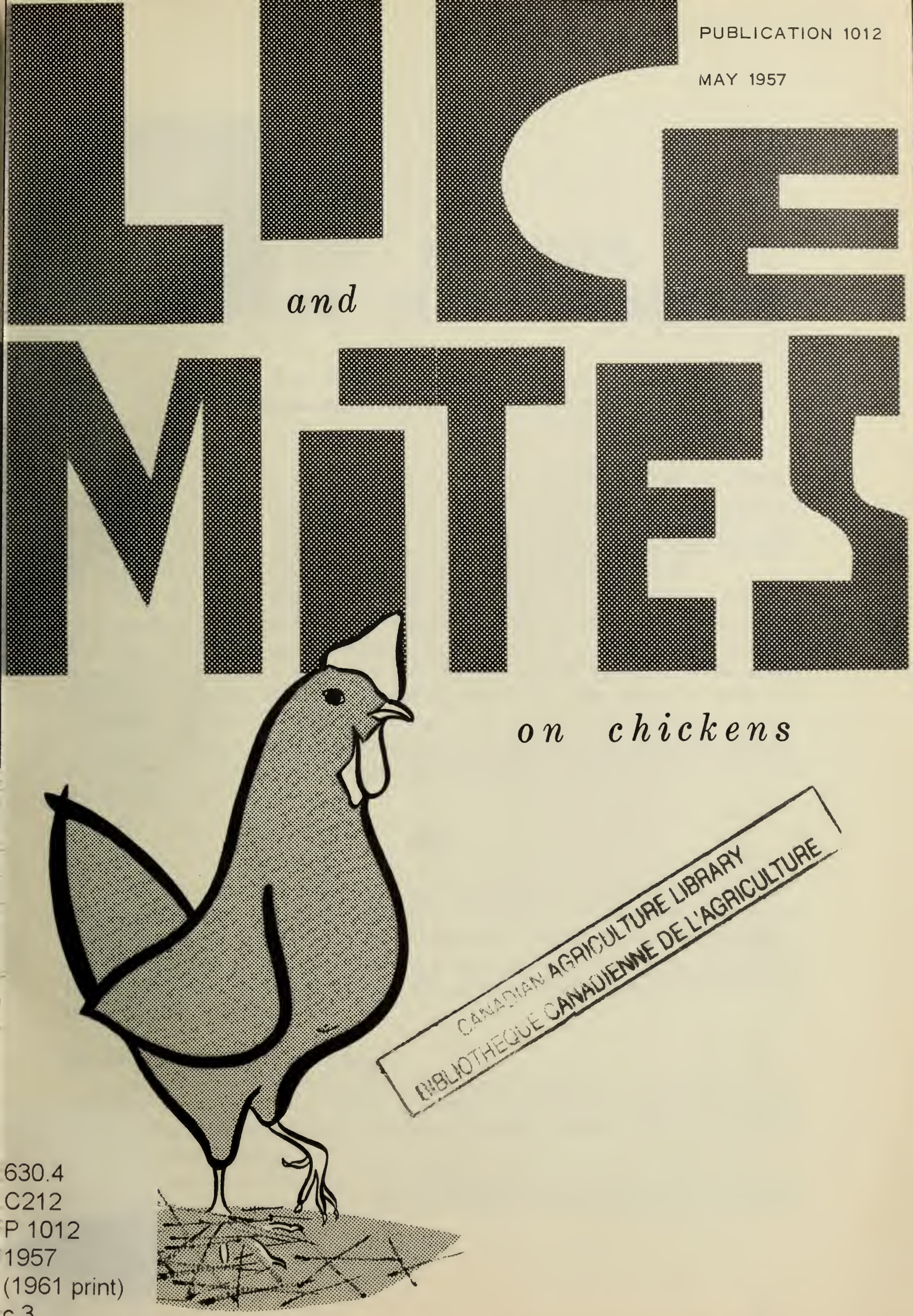
Digitized by the Internet Archive in 2012 with funding from

Agriculture and Agri-Food Canada - Agriculture et Agroalimentaire Canada 


\title{
LICE AND MITES ON CHICKENS
}

\author{
P. E. Morrison and R. P. Thompson \\ Entomology Laboratory, ${ }^{*}$ Guelph, Ontario
}

Several species of lice and mites are serious pests of chickens in Canada. Infestations of these pests may damage plumage, retard growth, lower vitality, and reduce egg production; they may even cause death. Infested chickens may eat less, or, on the other hand, eat more as a result of the drain on their strength. The infested bird becomes weakened and more susceptible to disease.

Lice and mites reproduce rapidly during warm weather and may occur in great numbers. They may be spread from farm to farm by stray or newly purchased fowl, wild birds, crates, or coops, or on the clothing of persons working with infested poultry. Proper sanitation and other preventive measures, such as the screening of windows in poultry houses to prevent the entrance of wild birds, aid in keeping chickens free of infestations.

Since lice are insects, whereas mites are more closely related to spiders, the two groups differ greatly in appearance, life histories, habits, and control, and are discussed separately.

\section{LICE}

Seven species of lice may be found on poultry in Canada. These lice have chewing mouth parts and do not suck blood. They feed on the feathers, hair, loose scales, and scabs on the skin. They cause harm by constantly irritating the birds. Heavily infested chickens may appear droopy, with lowered wings and ruffled feathers. Examining birds periodically aids in discovering infestations before they reach harmful proportions.

\section{Appearance, Life History, and Habits}

Adult lice are yellowish brown or black and, depending on species, from an eighth to a sixteenth of an inch long. They have flattened bodies and broad, rounded heads. Their mouth parts include two sharp, pointed teeth, or mandibles, that are used in chewing.

The eggs are small, less than a thirty-second of an inch in diameter, oval, and whitish. They are commonly found in grayish clusters or masses attached to

\footnotetext{
Research Branch.
} 
the barbs of the feathers (Figure 1). They may be found on various parts of the body, depending on the species of lice. The eggs hatch in a few days to two weeks after being laid. They usually do not hatch on feathers removed from the bird. The newly hatched nymphs resemble the adults, but are smaller and paler. They molt, or shed their skins, several times before becoming adults, usually within three weeks.

The lice spend their entire lives on the birds, and cannot survive off them for more than seven to ten days. They do not live on humans for more than a day or two. They breed most readily in summer, but even in winter all stages of the life cycle, eggs, nymphs, and adults, may be found on the birds. Once established, they usually increase rapidly in numbers. When the feathers of an infested bird are parted, the lice may be seen running on the skin or clinging to the feathers.

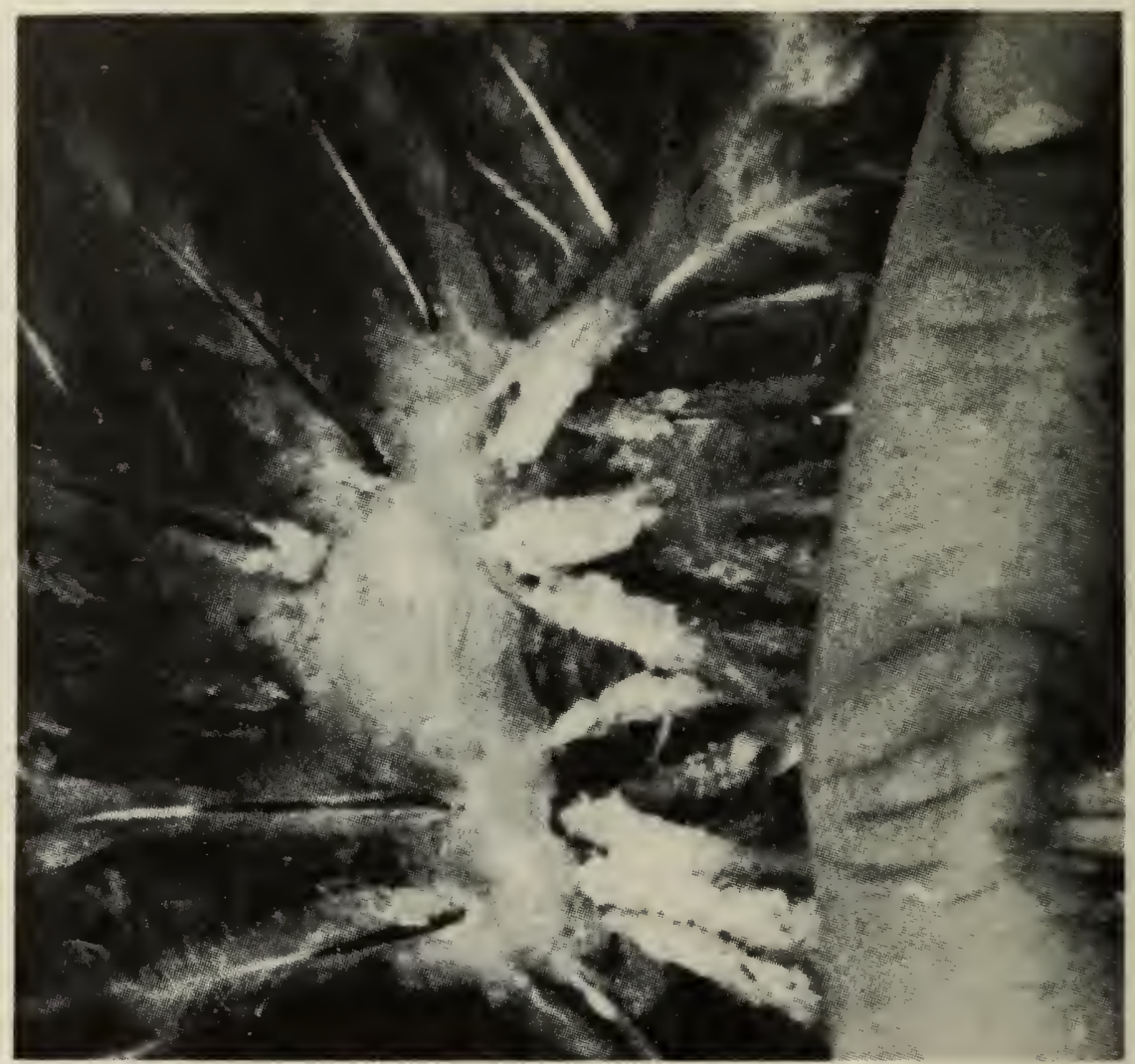

Figure 1.- Egg masses of the chicken body louse attached to feathers near the vent.

\section{Species of Lice on Chickens}

The chicken body louse ${ }^{1}$, the shaft louse ${ }^{2}$, and the fluff louse ${ }^{3}$ are the three most common species. The wing louse ${ }^{4}$ and the chicken head louse ${ }^{5}$ are also common in some parts of the country. Less common species are the large chicken louse ${ }^{6}$ and the brown chicken louse ${ }^{7}$. Chickens may often be infested with two or more species at the same time.

Chicken body louse.- The body louse is probably the most irritating of the species. It is about an eighth of an inch long. On full-grown chickens, it occurs

1 Menacanthus stramineus (Nit $\mathrm{z}_{\bullet}$ ).

Menopon gallinae (L.).

${ }_{4}^{3}$ Goniocotes gallinae (DeG.).

4 Lipeurus caponis (L.).

${ }_{6}^{5}$ Cuclotogaster heterographus (Nit z.).

${ }_{7}^{6}$ Goniodes gigas (Tasch.).

7 Goniodes dissimilis Denny. 
on the skin about the vent and often on the sides of the body. On young chickens it is more abundant on the back. Heavy infestations frequently cause a marked reddening of the skin. Even on lightly to moderately infested birds, the lice may be seen running for cover as the feathers are parted. The egg masses are commonly found on the feathers about the vent.

Shaft louse. - This species is similar in appearance to the chicken body louse but is smaller, being about a sixteenth of an inch long. It is common on the sides of the body, on the thighs, and about the vent, attached to the feathers in a head-down position. On heavily infested birds, it may also be found on the back. When the feathers are parted, the lice run to the skin. The eggs are attached to the bases of the feathers and hatch within two weeks.

Only older adult birds are liable to infestation by the shaft louse, probably because young birds lack mature feathers. Ducks, turkeys, and guinea hens may also become infested when housed with infested chickens.

Fluff louse. - This species is found on the birds where the feathers are fluffiest. It is a pale insect, about a twentieth of an inch long, with a roundish appearance. The fluff louse seldom occurs in large numbers and appears to be harmless.

Wing louse. - This is a slender, gray to black insect about a tenth of an inch long. It is commonly found attached to the large, primary wing feathers (Figure 2). Occasionally, it is found on the feathers on the neck.

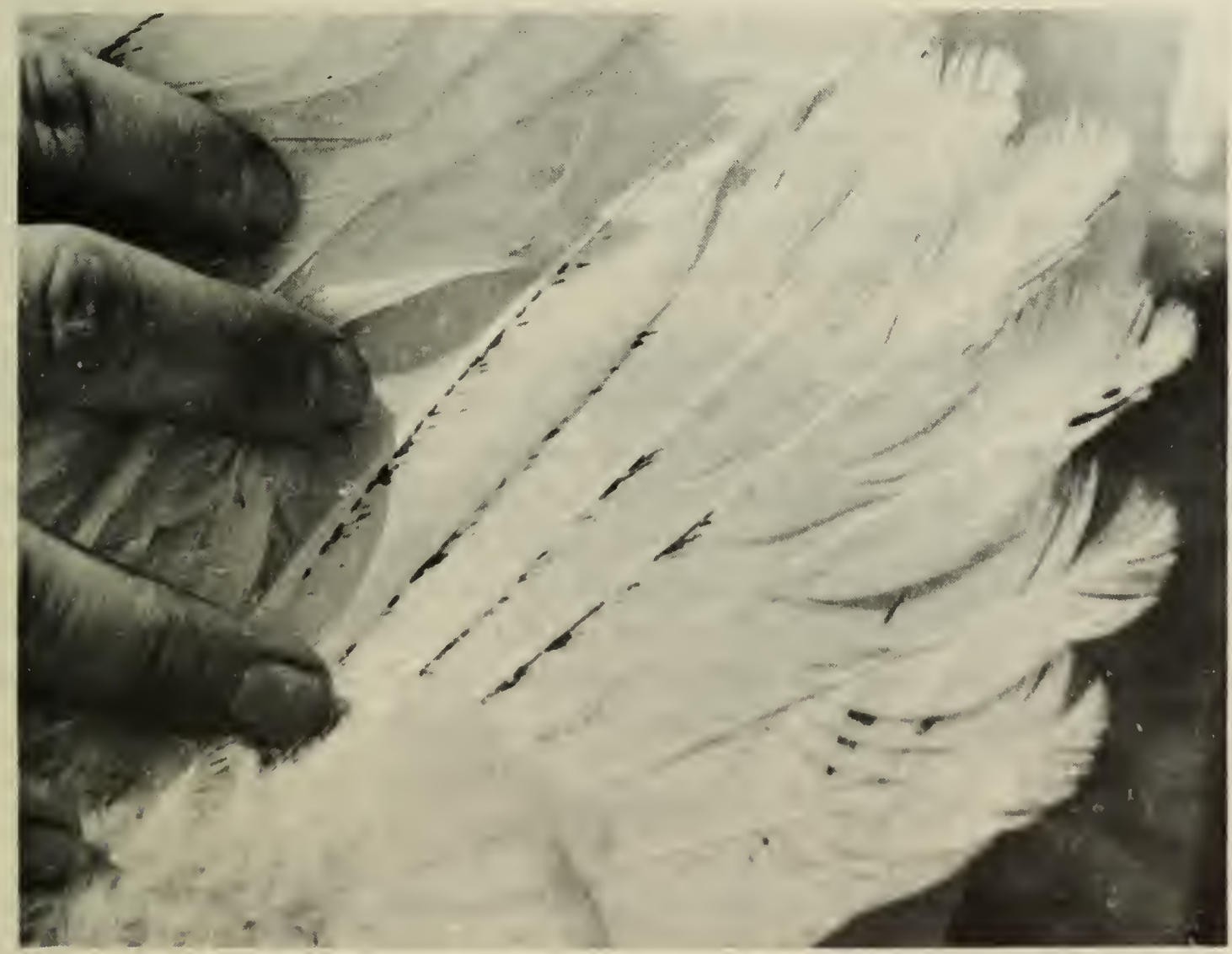

Figure 2. - Wing lice attached to the barbs of primary wing foathers. 
Chicken head louse.-This species is usually more numerous on young chickens. The lice are dark gray and about a tenth of an inch long. They hang head-down from the bases of feathers on top of the bird's head. The eggs are cemented to the barbs of down or small feathers on the chicken's head or neck. Hatching occurs in about 10 days. The head louse passes from the brooding hen to the chicks but thereafter moves about very little. It may be injurious to chicks and young turkeys that are heavily infested.

Other species. - The large chicken louse has a broad, smoky-gray to black body, about an eighth of an inch long. It occurs on the feathers in various body regions. The brown chicken louse, smaller then the large chicken louse, is reddish brown and is found on the body feathers.

\section{Control}

A single application of malathion is effective against all species of chicken lice. Apply it as a 4 per cent dust to the floor litter, roosts, and nest litter at the rate of 1 pound to 40 square feet. This is the simplest form of application, and is particularly recommended in cold weather. Broadcast the dust with a mechanical duster, a shaker can, or the gloved hand. In warm weather a 3 per cent malathion spray may be used. Prepare this by thoroughly mixing $2 \frac{1}{2}$ pints of a 50 per cent emulsible concentrate, or 6 pounds of a 25 per cent wettable powder, with 5 gallons of water. Apply the spray with a garden-type or power sprayer to floor litter, roosts, and nest litter in sufficient quantity to dampen them. Treat the sides as well as the tops of the roost bars. Lindane applied as a 0.5 per cent water emulsion spray is also effective. The birds need not be removed from the pen during any of these treatments.

Another method is to dust infested birds as a flock or individually with malathion. Apply a 4 per cent dust to a flock, with a rotary duster or a shaker can, at the rate of 1 pound to 100 birds. Or dust birds individually with a puff duster at the rate of 1 pound to 150 birds. Two puffs per bird are adequate if they are directed at the vent and the breast. Dusting is most effective for battery and range birds.

Applying roost paints is an alternative but less reliable control method. Paint or spray on the roosts a 3 per cent malathion water emulsion or wettable powder suspension at the rate of 20 fluid ounces per 50 lineal feet of roost. In addition, spray 1 per cent malathion on the nest litter to dampen it. Or apply lindane in a similar manner, a 1 per cent spray on the roosts at 20 fluid ounces per 200 lineal feet and a 0.5 per cent spray on the nest litter. Nicotine sulphate, 40 per cent, may also be used as a roost paint in well-ventilated buildings when the inside temperature exceeds $70^{\circ} \mathrm{F}$. Apply 16 fluid ounces to 200 feet of roost.

Control recommendations are summarized in Table 1

\section{MITES}

Three species of mites commonly infest chickens in Canada. Two species live on the host continaully. A third attacks the birds only at night, hiding in 


\begin{tabular}{|c|c|c|c|c|c|c|}
\hline 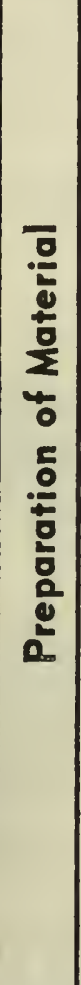 & 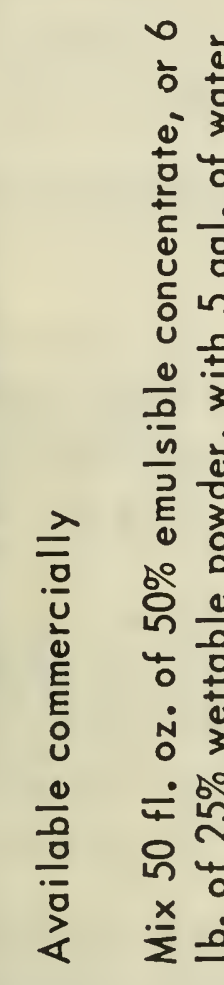 & 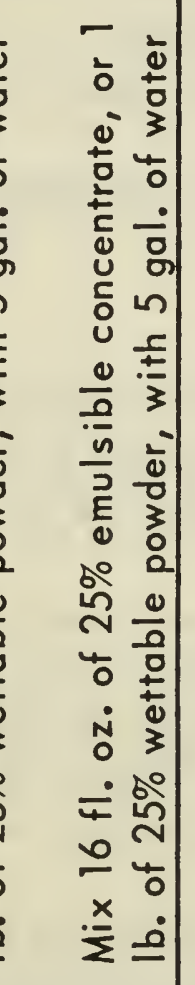 & 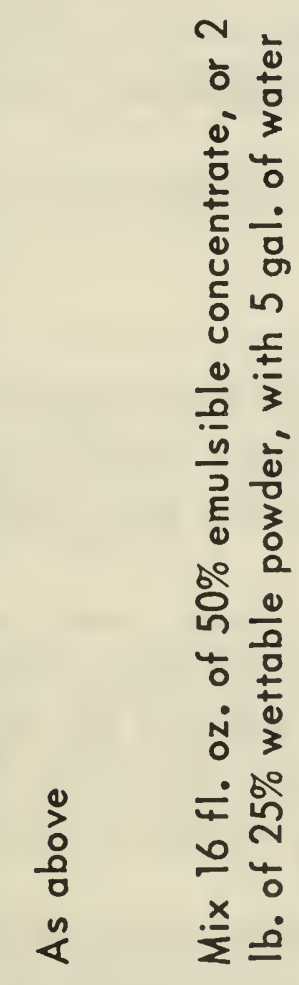 & 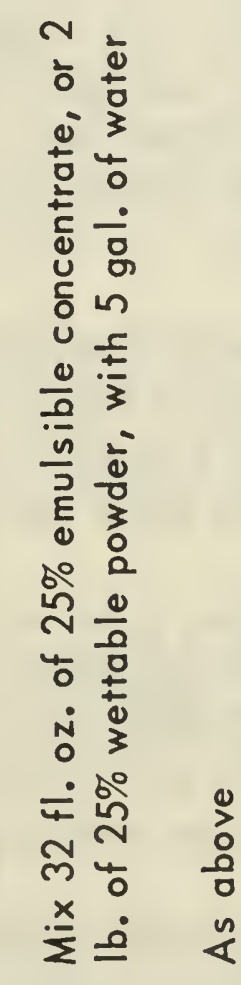 & 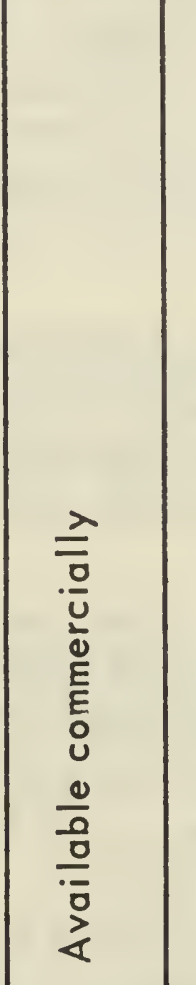 & 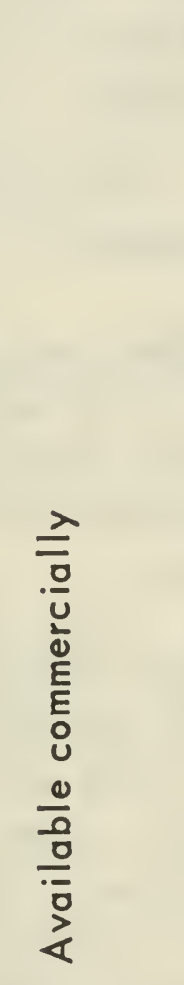 \\
\hline 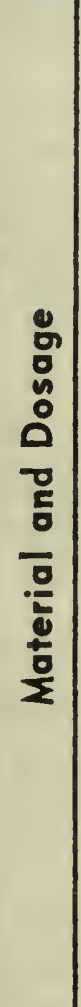 & 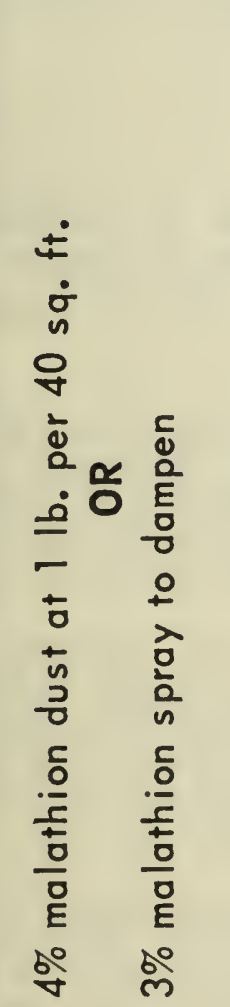 & 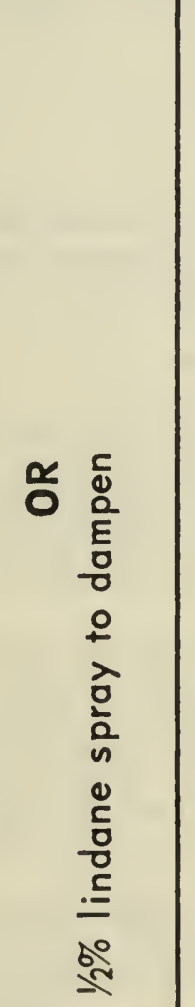 & 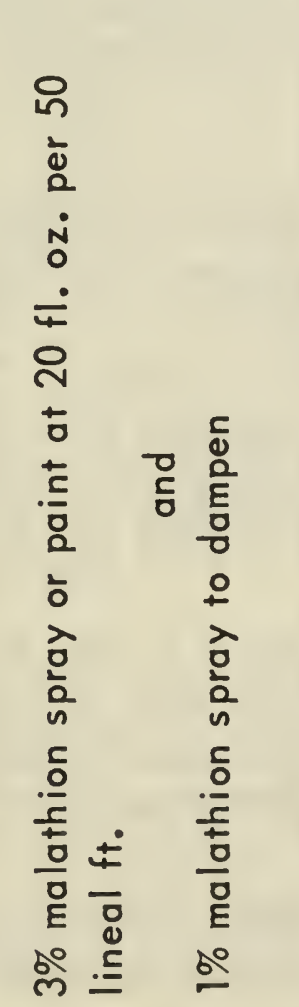 & 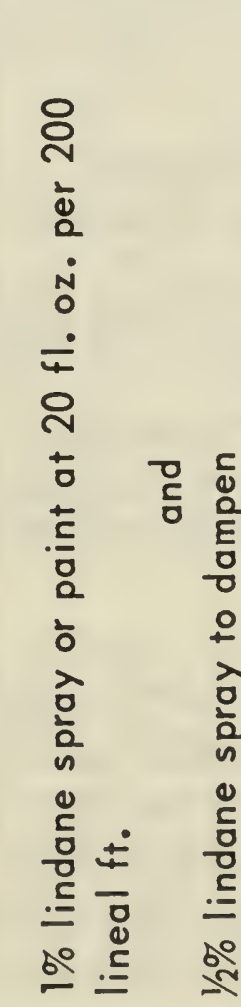 & 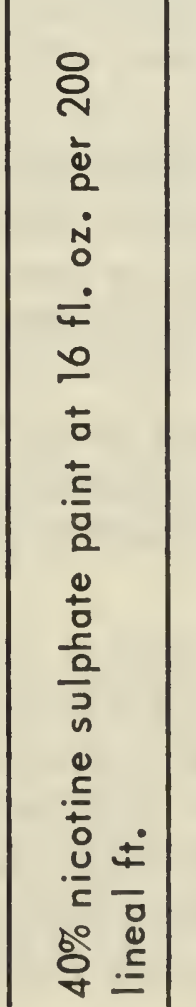 & 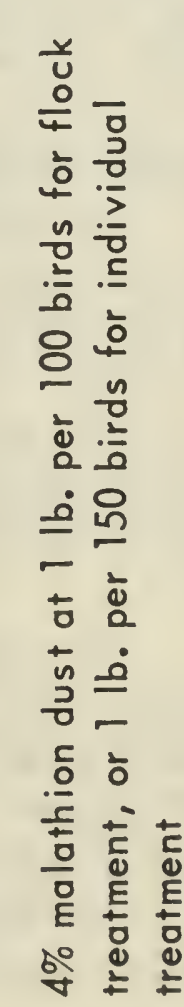 \\
\hline $\begin{array}{l}2 \\
\frac{2}{2} \\
\frac{a}{2} \\
\frac{2}{4}\end{array}$ & 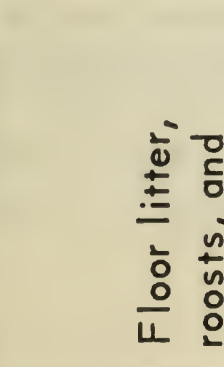 & $=$ & 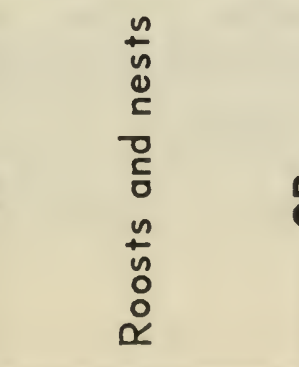 & 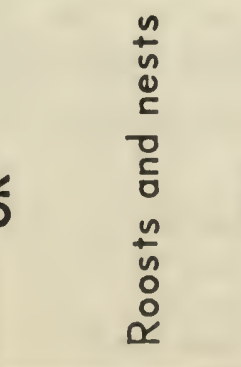 & 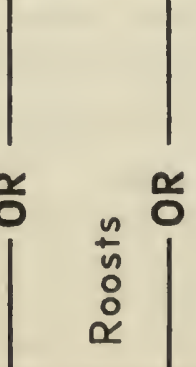 & $\frac{n}{\stackrel{n}{*}}$ \\
\hline
\end{tabular}


cracks during the day. All mites that infest poultry suck blood. Signs of infestation by mites may vary among flocks; nervousness and anemia are typical symptoms. A regular, thorough examination of the birds and chicken houses is necessary to reveal infestations.

Mites may spread Newcastle disease and are suspected of transmitting other diseases.

\section{Appearance, Life History, and Habits}

The adult mites have eight legs and range in color from light gray to reddish black. They vary in size from less than one-sixty-fourth to one-thirtieth of an inch in length. Their mouth parts are sharp and pointed for piercing the skin of the host.

Eggs of the poultry mite are minute, oval, and pearly-white. They are found where the adult mites congregate, and, hatch within a week. The newly hatched mite has six legs and otherwise resembles the adult. In growing, the mite sheds its skin several times and acquires eight legs. Soiled areas appear where the mites congregate in large numbers, whether in the cracks of the pen or among the feathers of the bird.

Poultry mites are more capable of surviving off their hosts than are chicken lice. The habits of these mites vary greatly between species. During cold weather, an infestation may remain inactive and unobserved. In warm weather, all stages are more active and the life cycles shorter.

\section{Species of Mites on Chickens}

The mites most commonly found infesting chickens in Canada are the chicken mite (or roost mite) ${ }^{8}$, the northern fowl mite (or feather mite) ${ }^{9}$, the scalyleg mite ${ }^{10}$, and the depluming mite ${ }^{11}$.

Chicken mite. - This mite, a thirtieth to a fortieth of an inch long, is most readily seen just after feeding on blood, when it is bright red. The color changes later to dark red or black. Mites that have not fed are gray and more difficult to see.

The chicken mite attaches itself to the bird at night, sucking blood and causing much discomfort. During the day, it lives in the joints and cracks of roosts, nesting boxes, and walls of chicken houses. These sites may have a salt and pepper appearance because of the presence of the mites, and their eggs, whitish skin casts, and excrement.

The chicken mite may live four or five months without food, even in the coldest weather. If empty brooder houses are heated before young birds are placed in them, the mites, if present, may be seen crawling about their hiding places.

Chickens seem to be the preferred host, but the mites may attach themselves to other domestic and wild birds, animals and man. In this way, infestations may be carried from flock to flock.

\footnotetext{
${ }_{9}^{8}$ Dermanyssus gallinae (DeG.).

10 Bdellonyssus sylviarum (C. \& F.).

10 Knemidokoptes mutans (R. \& L.).

Knemidokoptes gallinae (Raill.).
} 
Northern fowl mite. - This mite is about a fortieth to a fiftieth of an inch long, and is similar in appearance to the chicken mite. Its habits distinguish it from the latter, the northern fowl mite lives continuously on the bird and generally congregates near the vent, tail, and neck. The excreta and eggs of the mites may give a gray, peppery appearance to the feathers in these areas. An infestation of these mites may first be noticed by their presence on eggs and nesting litter.

Scaly-leg mite. - The scaly-leg mite is barely visible to the eye. It burrows into the flesh under the leg scales of chickens, where it sucks blood, and causes a thickening of the scales. Red blotches may form on infested areas and blood may exude. In time, infested birds may become crippled. This mite may also be found about the head and comb of the bird.

Depluming mite. - The depluming mite is about the same size as the scalyleg mite. It burrows into the skin at the bases of the feathers on rump, back, head, abdomen, and legs. Birds often pull out their feathers because of the irritation.

\section{Control}

Northern fowl mite.- Apply a 4 per cent malathion dust to floor litter at the rate of 1 pound to 40 square feet. Broadcast it with a mechanical duster, a shaker can, or the gloved hand. Another method is to dust infested birds as a flock or individually with malathion. Apply a 4 per cent malathion dust to a flock with a shaker can or a rotary duster at the rate of 1 pound to 100 birds. Or dust birds individually with a puff duster at the rate of 1 pound to 150 birds. Two puffs per bird are adequate if they are directed at the vent and the breast. Dusting is most effective for battery or range birds.

Nicotine sulphate, 40 per cent, may also be used to control this species. Paint it on roosts at the rate of 16 ounces per 200 lineal feet, half an hour before roosting time. The heat of the birds' bodies vaporizes the nicotine, which permeates the feathers. Best results are obtained when the air temperature is above $70^{\circ} \mathrm{F}$. Repeat the application in two weeks. Poultry houses must be well ventilated when nicotine sulphate is used.

Chicken mite. - Apply a 4 per cent malathion dust to the floor litter at the rate of 1 pound to 40 square feet and, in addition, spray a 1 per cent malathion water emulsion or wettable powder suspension on nests, walls, and roosting places at a dosage sufficient to dampen them. Or treat the floor litter, nests, and roosting places with a $2 \frac{1}{2}$ per cent DDT spray, prepared by mixing $2 \frac{1}{2}$ pounds of 50 per cent DDT wettable powder in 5 gallons of water. DDT takes longer than malathion to give control.

Scaly-leg mite. - Soak the shanks of the legs and feet of the birds in soapy water until the scales are loosened. Then dip or paint the legs and feet with a 0.1 per cent ( 1 part per 1000) lindane emulsion prepared from an emulsible concentrate. As an alternative to dipping or painting, grease the legs and feet with 


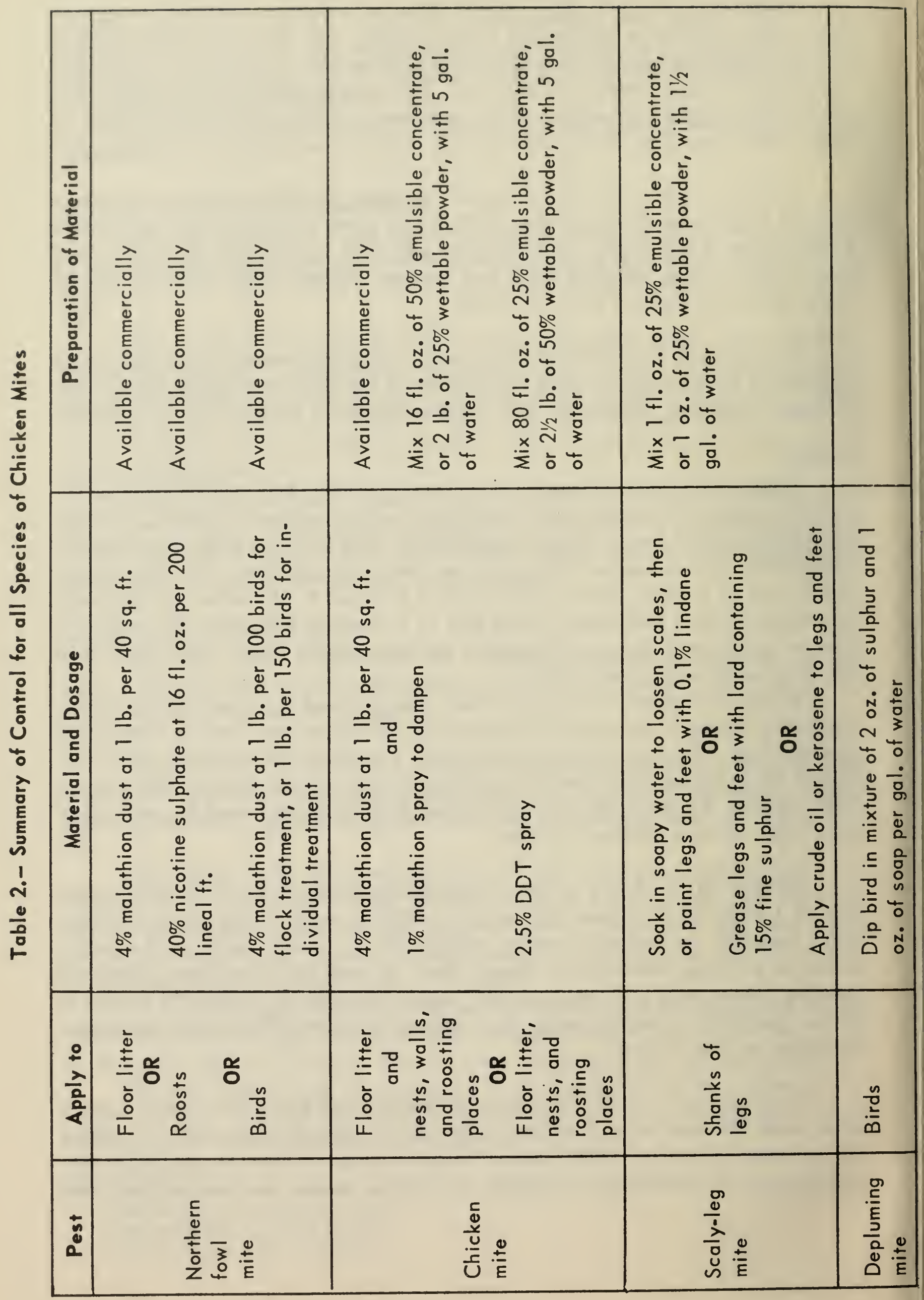


lard containing 15 per cent finely ground (micronized) sulphur. Or dip the lower legs in crude oil, repeating the treatment in one month if the distorted scales have not been shed.

Depluming mite.- Dip the birds in a mixture of 2 ounces of sulphur and 1 ounce of soap, or detergent, in a gallon of warm water. Repeat the treatment every 3 or 4 weeks.

Control recommendations are summarized in Table 2.

\section{INQUIRIES}

For more information, consult your agricultural representative or provincial entomologist, or write to the nearest insect laboratory of the Canada Department of Agriculture or to the Scientific Information Section, Canada Department of Agriculture, Central Experimental Farm, Ottawa.

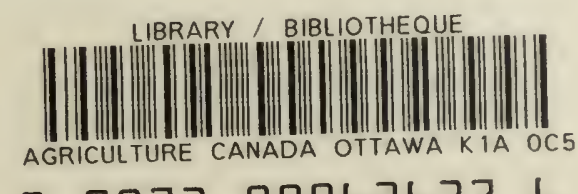

39073 00062b3? b 
First printed ............ May 1957

Reprinted........ December 1961

Copies of this publication are available from:

Information Division

CANADA DEPARTMENT OF AGRICULTURE

Ottawa, Ontario

ROGER DUHAMEL, F.R.S.C.

QUEEN'S PRINTER AND CONTROLLER OF STATIONERY OTTAWA, 1962 